\title{
Absorption, Fluorescence, and Thermal Properties of Transparent Polyimides Based on Cyclobutanetetracarboxylic Dianhydride
}

\author{
Qinghua Li, Kazuyuki HorIE, and Rikio YокотA* \\ The University of Tokyo, Graduate School of Engineering, Department of Chemistry \\ and Biotechnology, 7-3-1 Hongo, Bunkyo-ku, Tokyo 113-8656, Japan \\ *Institute of Space and Astronautical Science, 3-1-1 Yoshinodai, \\ Sagamihara, Kanagawa 229-8510, Japan \\ (Received February 5, 1998)
}

\begin{abstract}
Ultraviolet/visible absorption spectra and fluorescence spectra of transparent polyimides derived from 1,2:3,4-cyclobutanetetracarboxylic dianhydride (CBDA) with an aromatic diamine, 4,4'-diaminodiphenylmethane (DPM), a fluorinated diamine, 2,2-bis(4-diaminodiphenyl)hexafluoropropane (6FdA), and an alicyclic diamine, 4,4'-diaminodicyclohexylmethane (DCHM) were investigated, compared with their model compounds. Both monomer and excimer fluorescence were observed in concentrated $\mathrm{CH}_{2} \mathrm{Cl}_{2}$ solution of model compounds, suggesting head to tail intermolecular overlap structures at the excited state. All polyimide films derived from CBDA showed high transparency in the visible region, i.e., no absorption tail was found above $375 \mathrm{~nm}$. Especially, PI(CBDA/DCHM) showed the highest transparent property with almost no absorption above $310 \mathrm{~nm}$. Absorption shoulders at $235 \mathrm{~nm}$ of PI(CBDA/DPM) and PI(CBDA/6FdA) are due to the absorption of phenylene groups in the diamine moieties. The fluorescence spectra of all polyimide films studied showed the existence of ground-state complexes. Their excitation wavelength dependence would be due to the existence of various conformations of packing structure. The glass transition temperatures, $T_{\mathrm{g}}$, of these polyimides based on CBDA lie in the region of $277^{\circ} \mathrm{C}$ to $360^{\circ} \mathrm{C}$. These polyimides have decomposition temperatures around $450^{\circ} \mathrm{C}$ under deaerated conditions.

KEY WORDS Transparency / Polyimides / Alicyclic Dianhydride/Fluorescence / Excitation Wavelength Dependence / Packing Structure / Glass Transition Temperature
\end{abstract}

Polyimides (PI), one of typical high-performance materials, have been widely used as electrical insulators, coatings, adhesives, substrates for flexible printed circuits, because of their superior thermal, mechanical properties and low dielectric constants. ${ }^{1}$ In general, PI are prepared by a two-step process; first, diamines react with dianhydrides in aprotic polar solvents at room temperature to give poly(amide acid)s (PAA), the precursor of polyimides; secondly, PAA are converted to PI by either thermal or chemical imidization. Recently, New PI with various functional groups which show high solvent solubility, ${ }^{2-4}$ high photosensitivity, ${ }^{5-9}$ photoconductivity, ${ }^{10-12}$ have been actively investigated. Although polyimides have been widely used in microelectronics and the aerospace industry, their apparent color from yellow to brown has limited their application in optical communication and liquid crystal display devices.

Kotov et al. ${ }^{13}$ attributed the coloration of polyimide films mainly to the intermolecular charge-transfer (CT) complexes formed owing to molecular aggregation between PI chains in solid states. In order to obtain a transparent polyimide, the most important point is to eliminate the inter- and/or intramolecular CT formation in usual aromatic polyimides, where aromatic moieties from diamine act as electron donors and the imide moieties act as electron acceptors. PI derived from 2,2-bis(3,4-dicarboxyphenyl)hexafluoropropanedianhydride (6FDA), ${ }^{14-18}$ are well known to be very transparent. In recent years, Jin et al. ${ }^{19-21}$ reported that PI prepared from an alicyclic diamine, 4,4'-diaminodicyclohexylmethane (DCHM), show good transparency, photochemical and dielectric properties as well as good thermal stability. In our previous paper, ${ }^{22}$ ultraviolet/ visible (UV-Vis) absorption and fluorescence spectra were investigated for transparent PI, PI(6FDA/DCHM) and PI(6FDA/PDA), prepared from fluorinated dianhydride, 6FDA, with an alicyclic diamine, DCHM, as well as with $p$-phenylenediamine (PDA). Both PI(6FDA/ DCHM) and PI(6FDA/PDA) showed high transparency in the visible region, where no absorption band above $370 \mathrm{~nm}$ was found. The reason is that, by introducing 6FDA and/or DCHM to the polyimide main chain, the bulky substituent group $-\mathrm{C}\left(\mathrm{CF}_{3}\right)_{2}-$ prevents molecular packing in polyimide films, resulting in weakened intermolecular CT. Meanwhile, a weak electron donating property of the alicyclic diamine, DCHM, prevented the occurrence of both inter- and intramolecular charge transfer in polyimide films.

PI prepared from alicyclic dianhydride, 1,2:3,4cyclobutanetetracarboxylic dianhydride (CBDA) are also attracting much interest. Nakanishi et al. ${ }^{23}$ first prepared polyimides from CBDA with hexamethylenediamine or $p, p^{\prime}$-diaminodiphenylmethane. Moore et al. ${ }^{7}$ reported that polyimide, $\mathrm{PI}(\mathrm{CBDA} / \mathrm{ODA})$, prepared from CBDA and oxydianiline (ODA) showed intrinsic photosensivity which could be used for positive photoimaging. Ohkita et al. ${ }^{24}$ examined photocleavage reactions of model compounds having cyclobutane rings in the main chain, and reached the conclusion that the cyclobutane ring in the polyimides is photocleaved via the excited intramolecular CT where the aromatic moieties act as electron donors and imide rings act as electron acceptors. Although the PI derived from CBDA are used as a liquid crystal (LC) alignment layer, ${ }^{25,26}$ their transparency, fluorescence, and thermal properties have not been investigated or reported yet.

In the present study, transparent polyimides based on CBDA with an aromatic diamine, 4,4'-diaminodiphenylmethane (DPM), a fluorinated diamine, 2,2-bis(4- 
diaminodiphenyl)hexafluoropropane $(6 \mathrm{FdA})$, and an alicyclic diamine, DCHM, were prepared and their spectroscopic and thermal properties are studied. Their $\mathrm{UV}-\mathrm{Vis}$ and fluorescence spectra as well as those of their model compounds give an insight into the microstructures of the polyimide films based on CBDA.

\section{EXPERIMENTAL}

\section{Materials}

CBDA was kindly supplied by Nissan Chem. Co., and used without further purification. The reagent grade DPM and 6FdA were recrystallized from ethanol and dried under vacuum at $50^{\circ} \mathrm{C}$ for $24 \mathrm{~h}$. DCHM was obtained from Wako Chemical and used without further purification. Succinic anhydride (SA) was recrystallized in distilled acetic anhydride, and dried at $50^{\circ} \mathrm{C}$ under vacuum for $24 \mathrm{~h}$. Succinimide (SI) and $N$-methylsuccinimide (MSI) were recrystallized in benzene. Aniline (A) was used for reaction with SA to prepare $N$-phenylsuccinimide (PSI).

Solvent used for the preparation of PAA and their model compounds was $N, N$-dimethylacetamide (DMAc) which was distilled before use and stored with a molecular sieve. Spectroscopic grade dichloromethane $\left(\mathrm{CH}_{2} \mathrm{Cl}_{2}\right)$ was used for measuring the $\mathrm{UV}-\mathrm{V}$ is absorption spectra of model compounds.

\section{Preparation of Poly(amide acid)s (PAA) and Polyimides $(P I)$}

PAA were prepared following the usual procedure ${ }^{27}$ using a $100 \mathrm{ml}$ three neck round-bottom flask fitted with a mechanical stirrer, nitrogen inlet and a drying tube. A typical procedure is as follows: DCHM $(1.034 \mathrm{~g}, 5.0$ mmol) was dissolved in DMAc $(18 \mathrm{ml})$ under nitrogen. CBDA $(0.996 \mathrm{~g}, 5.0 \mathrm{mmol})$ was then added and the mixture was kept stirred at $0^{\circ} \mathrm{C}$ for $1 \mathrm{~h}$. The mixture was continuously stirred for $24 \mathrm{~h}$ at room temperature to produce a viscous and homogeneous PAA solution.

The resulting PAA(CBDA/DCHM) was cast on a glass plate, and dried under vacuum at room temperature for $6 \mathrm{~h}$. The film was peeled off the glass plate, and dried again under vacuum at $50^{\circ} \mathrm{C}$ for $24 \mathrm{~h}$. The PAA film was heated stepwise at $160^{\circ} \mathrm{C}, 200^{\circ} \mathrm{C}$, and $240^{\circ} \mathrm{C}$ for $1 \mathrm{~h}$, respectively. The almost complete conversion of the PAA to the corresponding PI was ascertained by IR spectra. The films of other polyimides such as $\mathrm{PI}(\mathrm{CBDA} / 6 \mathrm{FdA})$, $\mathrm{PI}(\mathrm{CBDA} / \mathrm{DPM})$ were prepared by the same procedure as for PI(CBDA/DCHM). These films were used for measurement of fluorescence and thermal properties. The limiting viscosity numbers, $[\eta]$, of the PAAs are 0.47 $\mathrm{dl} \mathrm{g}^{-1}$ for PAA(CBDA/DCHM), $0.64 \mathrm{dl} \mathrm{g}^{-1}$ for PAA(CBDA/DPM), and $0.53 \mathrm{dlg}^{-1}$ for PAA(CBDA/6FdA) which were measured in DMAc at $30^{\circ} \mathrm{C}$. The chemical structures of polyimides are illustrated in Scheme 1.

\section{Preparation of a Model Compound}

A model compound, PSI, was prepared by reacting SA $(1.035 \mathrm{~g}, 10.35 \mathrm{mmol})$ with A $(0.94 \mathrm{ml}, 10.35 \mathrm{mmol})$ in DMAc $(18 \mathrm{ml})$ at room temperature under nitrogen atmosphere for $5 \mathrm{~h}$. Then $4.2 \mathrm{ml}$ pyridine and $3.2 \mathrm{ml}$ acetic anhydride were dropped into the reaction solution, and the solution was kept stirred at $60^{\circ} \mathrm{C}$ under nitrogen

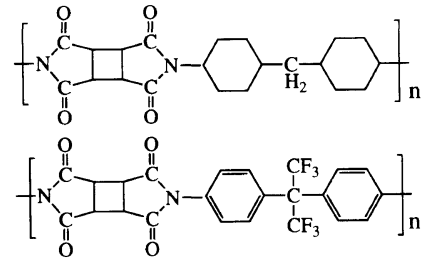

\author{
PI(CBDA/DCHM) \\ PI(CBDA/6FdA)
}

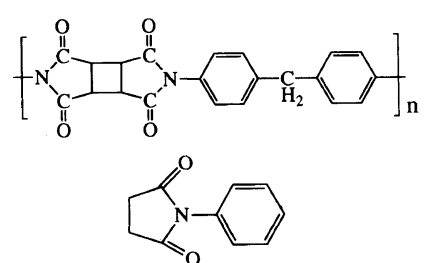

PI(CBDA/DPM)

PSI

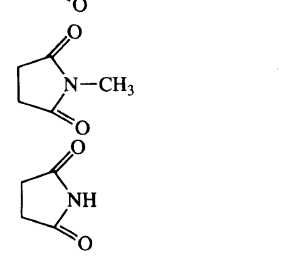

MSI

Scheme 1. Structures of transparent polyimides and model compounds.

atmosphere overnight. After the reaction was completed, DMAc was evaporated under reduced pressure at $60^{\circ} \mathrm{C}$, and a light yellow crystal was obtained. After recrystallization in benzene, and filtration, a white crystal was obtained, which was dried under vacuum at $50^{\circ} \mathrm{C}$ overnight. The crystal was ascertained to be PSI by IR spectrum and melting point $\left(153-154^{\circ} \mathrm{C}\right)$.

\section{Measurement of $U V$-Vis and Fluorescence Spectra}

UV-Vis absorption spectra were measured with a JASCO V-570 UV/VIS/NIR spectrophotometer for PIs and PAAs on quartz wafers. The samples were spincoated from $2.5 \%$ DMAc solutions of PAAs on quartz wafers, then dried under vacuum for $24 \mathrm{~h}$, and heated to imidization with the same conditions as for the peeled films. Absorption intensity was normalized with the film thickness measured with a topographically measured optical/laser microscope. Fluorescence spectra were measured with a fluorescence spectrophotometer (Hitachi Model 850) for films peeled off the glass plates. No photodegradation was observed in the present experimental conditions. The UV-Vis and fluorescence spectra of model compounds were measured in $\mathrm{CH}_{2} \mathrm{Cl}_{2}$ solution.

\section{Measurement of Thermogravimetry (TG), Thermo- mechanical Analysis (TMA), and Differential Scanning Calorimetry (DSC)}

The thermal characteristics of the polyimides were measured with TG, TMA, and DSC. TG was measured with a Thermal Analysis Instruments 2050 thermogravimetric analyzer at a heating rate of $10^{\circ} \mathrm{C} \mathrm{min}^{-1}$ under nitrogen atmosphere up to $600^{\circ} \mathrm{C}$. TMA was carried out with a Rigaku Thermoflex TAS 200 thermomechanical analyzer. A $14 \mathrm{~mm} \times 3 \mathrm{~mm}$ ribbon shape sample was mounted between two chucks in the TMA equipment, and the distance between them was recorded under a fixed load ( $5 \mathrm{~g}$ for PI(CBDA/6FdA) and PI(CBDA/ $\mathrm{DCHM}), 10 \mathrm{~g}$ for $\mathrm{PI}(\mathrm{CBDA} / \mathrm{DPM})$ ) with increasing temperature $\left(10^{\circ} \mathrm{C} \mathrm{min}^{-1}\right)$ under nitrogen atmosphere. DSC was carried out with a Thermal Analysis Instru- 


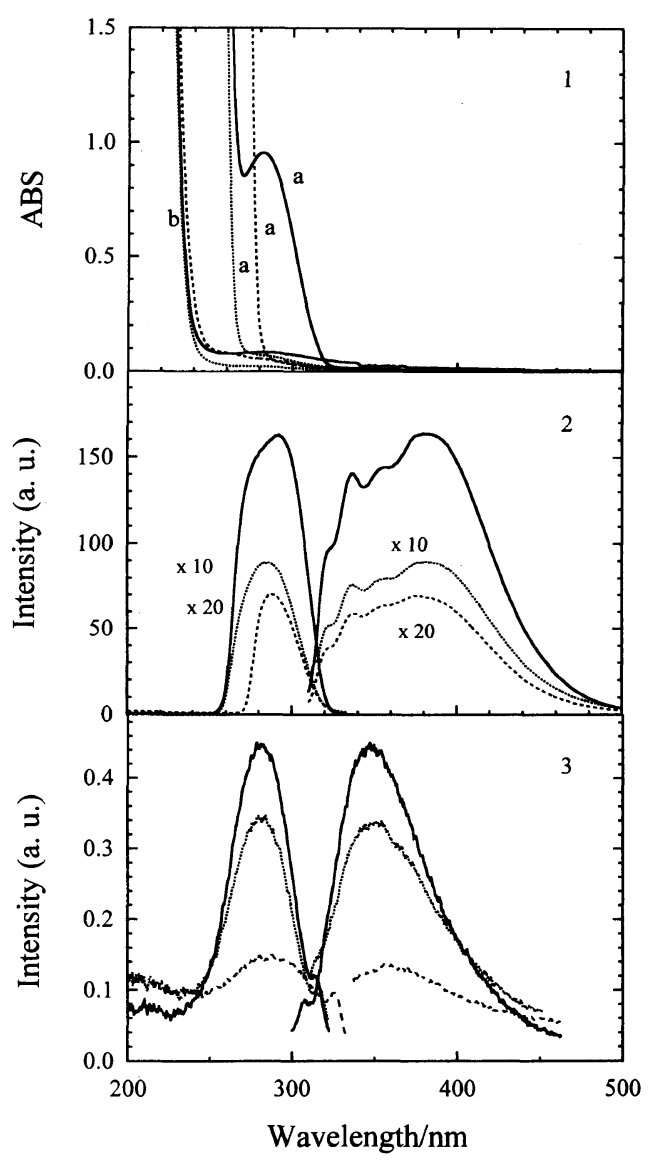

Figure 1. UV and fluorescence spectra of model compounds in $\mathrm{CH}_{2} \mathrm{Cl}_{2}$ solution. (1) $\mathrm{UV}$ absorption spectra in $9.3 \times 10^{-2} \mathrm{M}$ (a) and $9.3 \times 10^{-5} \mathrm{M}$ (b) solutions: - , SI; -...-., MSI; ---, PSI. (2) fluorescence spectra in $9.3 \times 10^{-2} \mathrm{M}$ solution: left, excitation spectra monitored at $380 \mathrm{~nm}$; right, emission spectra excited at $290 \mathrm{~nm} ;-$ SI; --..-., MSI; ---, PSI. (3) fluorescence spectra in $9.3 \times 10^{-5} \mathrm{M}$ solution: left, excitation spectra monitored at about $350 \mathrm{~nm}$; right, emission spectra excited at $280 \mathrm{~nm}$ (SI); $285 \mathrm{~nm}$ (MSI); and $300 \mathrm{~nm}$ (PSI); - - SI; -----, MSI; ---, PSI.

ments 2010 differential scanning calorimeter with a heating rate of $20^{\circ} \mathrm{C} \mathrm{min}^{-1}$ under nitrogen atmosphere up to $350^{\circ} \mathrm{C}$.

\section{RESULTS AND DISCUSSION}

\section{$U V$-Vis and Fluorescence Spectra of Model Compounds}

In order to elucidate the aggregate state of solid transparent polyimides, their model compounds; SI, MSI, and PSI, were used in this study. Figure 1.1 shows the ultraviolet/visible (UV-Vis) absorption spectra of model compounds at $9.3 \times 10^{-2} \mathrm{M}$ and $9.3 \times 10^{-5} \mathrm{M}$ $\mathrm{CH}_{2} \mathrm{Cl}_{2}$ solutions. For $\mathrm{SI}$, an absorption peak was observed at $290 \mathrm{~nm}$, with the molar extinction coefficient, $\varepsilon$, of about $100 \mathrm{M}^{-1} \mathrm{~cm}^{-1}$, which lies in the region of $n-\pi^{*}$ transition. So we can assign this absorption peak to $n-\pi^{*}$ transition of imide carbonyl group. When the solution concentration was diluted, no absorption peak was found. For MSI and PSI, no absorption peak was found in concentrated $\left(9.3 \times 10^{-2} \mathrm{M}\right)$ or diluted $(9.3 \times$ $10^{-5} \mathrm{M}$ ) solutions.

Figures 1.2 and 1.3 show the fluorescence excitation and emission spectra of model compounds in $9.3 \times$ $10^{-2} \mathrm{M}$ and $9.3 \times 10^{-5} \mathrm{M} \mathrm{CH}_{2} \mathrm{Cl}_{2}$ solutions, respectively. As it can be seen in the concentrated solutions,
Table I. Emission and excitation peak wavelengths of model compounds

\begin{tabular}{|c|c|c|c|}
\hline \multirow{2}{*}{ Model compounds } & \multicolumn{2}{|c|}{$\begin{array}{l}\text { Emission peak } \\
\text { wavelength/nm }\end{array}$} & \multirow{2}{*}{$\begin{array}{c}\text { Excitation } \\
\text { peak } \\
\text { wavelength } / \\
\mathrm{nm}\end{array}$} \\
\hline & Monomer & Excimer & \\
\hline Succinimide (SI) & 348 & 382 & $280-290$ \\
\hline$N$-Methylsuccinimide (MSI) & 350 & 383 & 285 \\
\hline$N$-Phenylsuccinimide (PSI) & 354 & 377 & 289 \\
\hline
\end{tabular}

SI gives broad emission spectra from $300 \mathrm{~nm}$ to $500 \mathrm{~nm}$, with peaks at around $330 \mathrm{~nm}, 360 \mathrm{~nm}, 380 \mathrm{~nm}$. The excitation spectra monitored at $330 \mathrm{~nm}$ (not shown in the figure) and $380 \mathrm{~nm}$ show a same peak at around $290 \mathrm{~nm}$ similar to that of the absorption spectrum in Figure 1.1. In the dilute solution $\left(9.3 \times 10^{-5} \mathrm{M}\right)$, the emission peak of SI is found at $355 \mathrm{~nm}$, which can be assigned as monomer emission of SI molecules. When monitored at $350 \mathrm{~nm}$, the excitation peak is found at $280 \mathrm{~nm}$, almost at the same wavelength as in the concentrated solution in Figure 1.2. The observation of a similar excitation peak for fluorescence at $380 \mathrm{~nm}$ in the concentrated solution and that at $355 \mathrm{~nm}$ in the diluted solution suggests that the emission at $380 \mathrm{~nm}$ in Figure 1.2 is due to the excimer formation between SI molecules at the excited state. Fluorescence spectra of MSI and PSI also show excimer emission at around $380 \mathrm{~nm}$ and monomer emission around $355 \mathrm{~nm}$. The emission and excitation peak wavelengths of these three model compounds are summarized in Table I.

As are shown in Table I, the excimer spectra of SI, MSI, PSI appear at about the same wavelength. Consequently, we can presume that the excimer emission are due to the head-to-tail overlap of two imide rings, since no effect of steric hindrance of the $N$-substituent groups was observed. The fluorescence intensity of SI, MSI, and PSI in the concentrated solution decreases markedly from SI to MSI and PSI. The electron donating property of the $\mathrm{N}$-substituents changes in the order of phenyl group $>$ methyl group $>-\mathrm{H}$. The imide ring has an electron accepting property though SI has no aromatic ring. So it is supposed that at the excitation state of PSI and MSI, intra- or intermolecular CT occurs, resulting in increase in non-radiative deactivation of the excitation state. $^{28}$

\section{UV-Vis Absorption Spectra of Films}

Figure 2a shows the UV-Vis absorption spectra of thin films of PI(CBDA/DPM), PI(CBDA/6FdA), and $\mathrm{PI}(\mathrm{CBDA} / \mathrm{DCHM})$, which are normalized with a film thickness of $0.3 \mu \mathrm{m}$. Spectra of both PI(CBDA/DPM) and PI(CBDA/6FdA) have no absorption band above $375 \mathrm{~nm}$, and that of PI(CBDA/DCHM) has almost no absorption band above $310 \mathrm{~nm}$, which means all polyimides derived from alicyclic dianhydride CBDA together with PI(CBDA/DPM), PI(CBDA/6FdA), and PI(CBDA/DCHM) show highly transparent properties in the visible region. This is due to the weak electron accepting property of the alicyclic imide moieties originating from CBDA, which weakens the intra- or intermolecular charge transfer that occurs in the conventional aromatic polyimides. Above $300 \mathrm{~nm}$, weak 


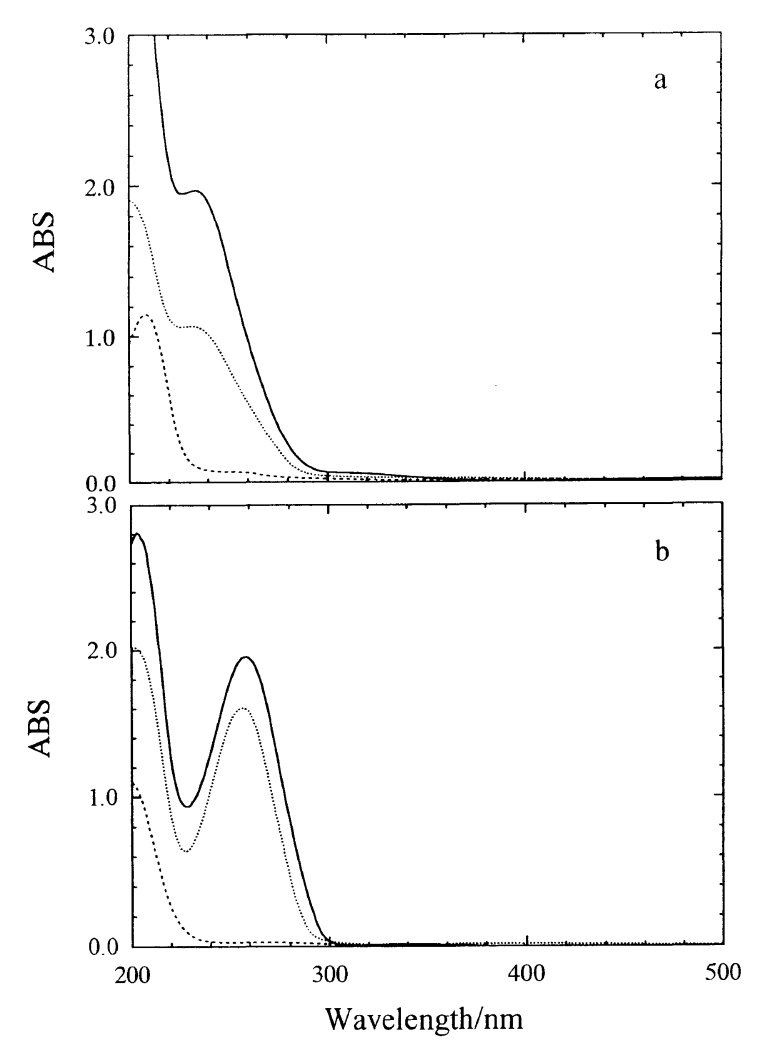

Figure 2. UV absorption spectra of polyimides (a) and poly(amide acid)s (b) thin films of $c a .0 .3 \mu \mathrm{m}$ thick, (CBDA/DPM) (CBDA/6FdA) -..-., and (CBDA/DCHM) - - .

absorption tails in $\mathrm{PI}(\mathrm{CBDA} / \mathrm{DPM})$ and $\mathrm{PI}(\mathrm{CBDA} /$ 6FdA) are observed. The absorption tail of PI(CBDA/ $\mathrm{DPM})$ is bigger than that of $\mathrm{PI}(\mathrm{CBDA} / 6 \mathrm{FdA})$. Weak ground-state charge transfer complex based on weak electron accepting property of CBDA may thus be formed in both PI(CBDA/DPM) and PI(CBDA/6FdA) films. Moreover, a bulky substituent group $-\mathrm{C}\left(\mathrm{CF}_{3}\right)_{2}-$ exists in $6 \mathrm{FdA}$, tight molecular packing in $\mathrm{PI}(\mathrm{CBDA} /$ $6 \mathrm{FdA}$ ) would be prevented, thus resulting in weak intermolecular interaction.

PI(CBDA/DPM) and PI(CBDA/6FdA) have absorption peaks at $236 \mathrm{~nm}$ and $235 \mathrm{~nm}$, respectively, almost at the same wavelength. This suggests that these peaks are due to the absorption of phenylene groups of the diamine moieties, as the dianhydride belongs to alicyclic compounds. The difference in absorption intensity between PI(CBDA/DPM) and PI(CBDA/6FdA) may be explained by different electron attracting properties of the substituents for phenylene groups. The $6 \mathrm{FdA}$, which has a bulky substituent group $-\mathrm{C}\left(\mathrm{CF}_{3}\right)_{2}-$ between two phenylene groups, would reduce the electron density of the phenylene groups, owing to the strong electron negativity of fluorine atoms.

As can be seen in Figure 2a, PI(CBDA/DCHM) has an absorption peak at $210 \mathrm{~nm}$, and shows almost no absorption above $310 \mathrm{~nm}$, which exhibits extremely transparent property in almost all UV-Vis regions. This can be explained by the weak electron donating property of alicyclic diamine, DCHM, ${ }^{29}$ and the weak electron accepting property of alicyclic dianhydride, CBDA, resulting in elimination of intra- and intermolecular charge transfer formation.

The UV-Vis absorption spectra of thin films ( $c a$.
$0.3 \mu \mathrm{m})$ of PAA(CBDA/DPM), PAA(CBDA/6FdA $)$, and PAA(CBDA/DCHM) are shown in Figure 2b. Comparing to the absorption spectra of $\mathrm{PI}(\mathrm{CBDA} / \mathrm{DPM})$ in Figure 2a, PAA(CBDA/DPM) shows an absorption peak at $260 \mathrm{~nm}$, while PI(CBDA/DPM) shows an absorption peak at $236 \mathrm{~nm}$, which means a blue shift of $24 \mathrm{~nm}$ when the poly(amide acid) is imidized to the polyimide. Sung et $a l .{ }^{30}$ studied the UV spectra of a model imide derived from 1,5-diaminonaphthalene (DAN) and phthalic anhydride, and found a blue shift of spectra when the amide acid was converted to an imide. In the present study, we used an alicyclic dianhydride, CBDA, which has no absorption in UV-Vis region. Thus, the absorption peak of $236 \mathrm{~nm}$ is due to the absorption of the diamine moiety in PI(CBDA/DPM). In PAA partial contribution of enolization of amide bond ${ }^{31}(-\mathrm{C}(\mathrm{OH})=\mathrm{N}-)$ would extend the delocalization of electrons, which results in a red shift of the absorption spectra of PAA(CBDA/DPM). Another reason for the blue shift when the poly(amide acid) is converted to the polyimide is that the electron donating property of amide bond is bigger than imide bond, which increases the $n-\pi$ conjugation between amide nitrogen and phenyl group in PAA(CBDA/DPM). The absorption above $300 \mathrm{~nm}$ for PI(CBDA/DPM) is bigger than for PAA(CBDA/DPM). After imidization by $160^{\circ} \mathrm{C}, 200^{\circ} \mathrm{C}$, and $240^{\circ} \mathrm{C}$ for $1 \mathrm{~h}$ each, molecular aggregation of $\mathrm{PI}(\mathrm{CBDA} / \mathrm{DPM})$ is improved, compared to $\mathrm{PAA}(\mathrm{CBDA} / \mathrm{DPM})$, resulting in increase in intermolecular CT formation.

The blue shift of absorption peak after imidization was also found in PI(CBDA/6FdA) and PAA(CBDA/ $6 \mathrm{FdA})$ films. A reduction of absorption intensity of PI(CBDA/6FdA) was also observed. No distinct difference in absorption tails was found between these films.

Both CBDA and DCHM are alicyclic compounds, thus PI(CBDA/DCHM) shows absorption peak only at $210 \mathrm{~nm}$ which corresponds to the absorption of imide rings. The small red shift of PI(CBDA/DCHM) compared to $\mathrm{PAA}(\mathrm{CBDA} / \mathrm{DCHM})$ is due to the formation of imide rings.

\section{Fluorescence Spectra of Polyimide Films}

Fluorescence spectroscopy is usually used for investigating the microstructures or aggregate structures of polymers, ${ }^{32-35}$ because it is very sensitive to changes of microenvironments of chromophore moieties in polymer matrices. Figure 3 shows the fluorescence spectra of PI(CBDA/DCHM) film with a thickness of $50 \mu \mathrm{m}$. When excited at $324 \mathrm{~nm}$, an emission peak is observed at $424 \mathrm{~nm}$. When excited at $370 \mathrm{~nm}, 390 \mathrm{~nm}, 410 \mathrm{~nm}, 430 \mathrm{~nm}, 450$ $\mathrm{nm}, 470 \mathrm{~nm}$, respectively, red shifts of emission peaks from $430 \mathrm{~nm}$ to $524 \mathrm{~nm}$ are observed, showing marked excitation wavelength dependence of the emission peak. No monomer fluorescence was found which appeared in the fluorescence spectra of model compounds.

The marked excitation wavelength dependence has also been observed in the fluorescence spectra of 6FDAcontaining polyimides, PI(6FDA/DCHM) and PI $(6 \mathrm{FDA} / \mathrm{PDA}),{ }^{22}$ as well as in those of paracrystalline solid of a liquid crystalline aromatic polyester. ${ }^{34}$ This is a special phenomenon in transparent polyimide films, compared to the fluorescence of conventional aromatic polyimides. ${ }^{33,36,37}$ Frank et al. ${ }^{36,37}$ investigated the 


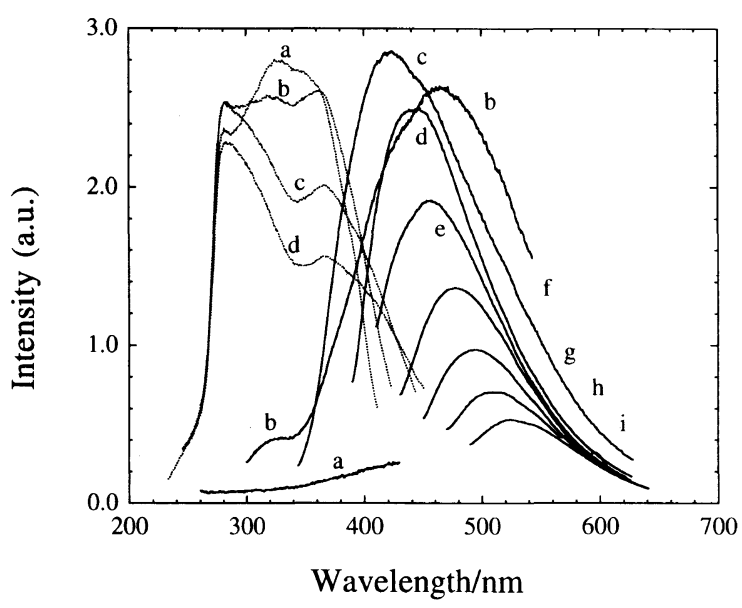

Figure 3. Fluorescence spectra of PI(CBDA/DCHM) film $(50 \mu \mathrm{m}$ thick) imidized at $160^{\circ} \mathrm{C}, 200^{\circ} \mathrm{C}$, and $240^{\circ} \mathrm{C}$. - : emission spectra excited at (a) $240 \mathrm{~nm}$, (b) $280 \mathrm{~nm}$, (c) $324 \mathrm{~nm}$, (d) $370 \mathrm{~nm}$, (e) $390 \mathrm{~nm}$, (f) $410 \mathrm{~nm}$, (g) $430 \mathrm{~nm}$, (h) $450 \mathrm{~nm}$, and (i) $470 \mathrm{~nm}$, respectively; -...--: excitation spectra monitored at (a) $424 \mathrm{~nm}$, (b) $450 \mathrm{~nm}$, (c) $480 \mathrm{~nm}$, and (d) $500 \mathrm{~nm}$, respectively.

degree of cure of PI(PMDA/ODA) film with fluorescence spectroscopy where PMDA denotes pyromellitic dianhydride, and reported that fluorescence intensity increased with increasing cure temperature. They assigned their emission spectra to the emission of charge transfer complex in the excited state which was formed between excited pyromellitimide moiety as an electron acceptor and diphenyl ether moiety as an electron donor. Hasegawa et al. ${ }^{33}$ reported that in PI(BPDA/PDA) derived from biphenyltetracarboxylic dianhydride (BPDA) and PDA, annealing induces not only increase in emission intensity at $525 \mathrm{~nm}$ but also the appearance of a new emission spectra at $540 \mathrm{~nm}$, which they assigned to emission of a ground-state intermolecular CT complex and considered this is due to increase in degree of molecular packing resulting from annealing. Hasegawa et $a{ }^{33}$ found a red shift of the emission peak after another thermal annealing, possibly be due to the appearance of another packing structure. However the excitation wavelength dependence of fluorescence in a same sample as is shown in Figure 3 was not observed for PI(BPDA/PDA). Thus we suggest that this excitation wavelength dependence of emission spectra is a specific phenomenon to the present polyimide films. In Figure 3 two excitation peaks are observed for the PI(CBDA/ DCHM) film, one is at $324 \mathrm{~nm}$, the other is at $370 \mathrm{~nm}$. Strong fluorescence excitation occurs at $280-300 \mathrm{~nm}$, but sudden decrease at shorter wavelengths than $280 \mathrm{~nm}$ would be a ghost due to increase in absorbance of the thick $(50 \mu \mathrm{m})$ film. The shapes of the excitation spectra are different from that of the UV spectrum in Figure 2 and those of excitation spectra of the model compounds in Figures 1. Thus we presume that ground-state complexes with various energy levels exist in the PI(CBDA/ DCHM) film. When the film was irradiated by UV light, the ground-state complexes were excited to their excited states and emit at various wavelengths. We are not sure if energy transfer in the excited states occurs between the excited ground-state complexes. But we probably had better interpret the emission spectra to the direct emission from excited ground-state complexes, since the energy

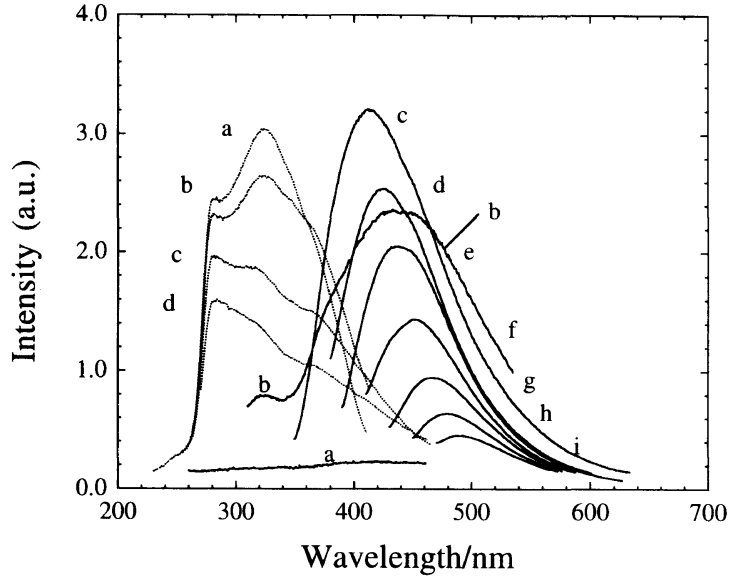

Figure 4. Fluorescence spectra of $\mathrm{PI}(\mathrm{CBDA} / \mathrm{DCHM})$ film $(50 \mu \mathrm{m}$ thick) imidized at $160^{\circ} \mathrm{C}$, and $200^{\circ} \mathrm{C}$. - emission spectra excited at (a) $240 \mathrm{~nm}$, (b) $280 \mathrm{~nm}$, (c) $324 \mathrm{~nm}$, (d) $350 \mathrm{~nm}$, (e) $370 \mathrm{~nm}$, (f) $390 \mathrm{~nm}$, (g) $410 \mathrm{~nm}$, (h) $430 \mathrm{~nm}$, and (i) $450 \mathrm{~nm}$, respectively; -...--.: excitation spectra monitored at (a) $427 \mathrm{~nm}$, (b) $450 \mathrm{~nm}$, (c) $480 \mathrm{~nm}$, and (d) $500 \mathrm{~nm}$, respectively.

difference between the ground and excited states of each complex is not monodisperse in amorphous solids and the red shift of the emission peak occurs regularly according to the shift of excitation wavelength.

It is of great interest that, when PI(CBDA/DCHM) film was excited at $280 \mathrm{~nm}$, its emission peak was found at a longer wavelength ((b) in Figure 3) apart from those for other excitation-wavelength-dependent emission spectra. However, when PI(CBDA/DCHM) film was imidized at $160^{\circ} \mathrm{C}$ and $200^{\circ} \mathrm{C}$ for $1 \mathrm{~h}$ each, the emission spectrum excited at $280 \mathrm{~nm}$ showed a peak at $436 \mathrm{~nm}$ (Figure 4) and became within the profiles of other excitation-wavelength-dependent emission spectra. The shift in emission peak is noticed only for the spectra excited at $280 \mathrm{~nm}$ where the monomeric imide moiety can be excited. This shift of emission peak excited at $280 \mathrm{~nm}$ with increasing imidization temperature suggests that the excited energy transfer from the excited singlet state of the monomeric imide moiety to a ground-state complex in PI(CBDA/DCHM) becomes a dominant process and the energy level and conformation of the complex to which energy transfer occurs differ by changing the imidization conditions. A minor peak observed at $322 \mathrm{~nm}$ for the emission excited at $280 \mathrm{~nm}$ in Figures 3 and 4 would correspond to monomer fluorescence of the imide moiety in PI(CBDA/DCHM). As CBDA and DCHM both are alicyclic compounds having configurational and conformational isomers, the micro-structures of the complexes in PI(CBDA/DCHM) would be complicated and of various types.

In conventional aromatic polyimides, two kinds of packing structures are proposed, ${ }^{38}$ "preferred layer packing" (PLP) in which the imide moieties of neighboring chains are aligned in a face-to-face fashion and "mixed layer packing". Proponents of the latter often argue that charge transfer forces are significant and give rise to a packing arrangement whereby the imide ring of one chain and the (amine) phenyl ring of another chain adopt a coplanar "sandwich" conformation.

In the present case of PI(CBDA/DCHM), the cyclobutanediimide moiety is a mixture of two configurational 


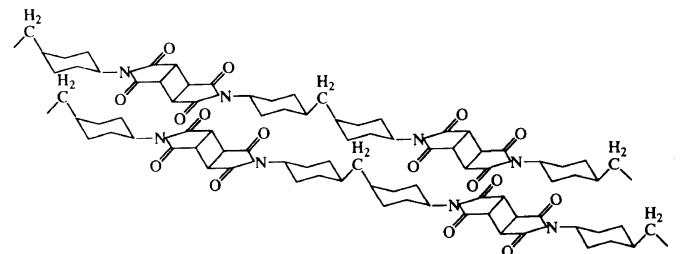

Figure 5. An example of the packing structures in PI(CBDA/DCHM) film.

isomers; trans-diimide and cis-diimide. DCHM ${ }^{19}$ is also a mixture of trans-trans, trans-cis, and cis-cis isomers as to the 1,4-disubstituted cyclohexane moiety. The observation of excimer fluorescence at the same wavelength for three model compounds (Figure 1) suggests that the head-to-tail overlap is favorable to the intermolecular dimer interaction between alicyclic imide moieties. Fluorescence spectra (Figures 3 and 4) show the existence of intermolecular ground-state complexes of various energy levels. As DCHM shows weak electron donating property and CBDA shows weak electron attracting property, very weak intermolecular CT might also occur in the excited state. By considering these results, the packing arrangement of $\mathrm{PI}(\mathrm{CBDA} / \mathrm{DCHM})$ may be proposed as a mixed layer packing with the head-to-tail stacking of imide ring of one polymer backbone with that of another polymer backbone. An example of the local packing structure is shown in Figure 5. As both CBDA and DCHM have configurational and conformational isomers, coplanar packing is very difficult, and the conformation is suggested to include various non-coplanar packing structure due to various degrees of constraint formation. As is shown in UV spectra in Figure 2, the ground-state interaction is very weak, this kind of weak interaction would be strengthened at excited state because of the increased donating property of DCHM and accepting property of CBDA at the excited state. The existence of two peaks in fluoresecence excitation spectra at $324 \mathrm{~nm}$ and $370 \mathrm{~nm}$ and increase in the proportion of the peak at $370 \mathrm{~nm}$ by the annealing at higher imidization temperature $\left(240^{\circ} \mathrm{C}\right)$ in Figure 3 compared to the case in Figure 4 would be attributed to increase in more stable packing structure in $\mathrm{PI}(\mathrm{CBDA} / \mathrm{DCHM})$ by annealing probably with a partial contribution of CT nature.

Excitation wavelength dependence is also observed in emission spectra of PI(CBDA/DPM) and PI(CBDA/ $6 \mathrm{FdA}$ ) films, as shown in Figures 6 and 7 respectively. The packing structures of PI(CBDA/DPM) and PI(CBDA/6FdA) films are suggested to be similar to that of PI(CBDA/DCHM). In PI(CBDA/DPM), the fluorescence emission intensity decreased compared to that of PI(CBDA/ DCHM), as well as a red shift of the peak by $25 \mathrm{~nm}$, owing to the increase in CT contribution because of the strong electron donating property of DPM. On the other hand, in PI(CBDA/6FdA), emission intensity is almost the same as that of PI(CBDA/ DCHM). A bulky $-\mathrm{C}\left(\mathrm{CF}_{3}\right)_{2}-$ group in $6 \mathrm{FdA}$ moiety, together with the large electron negativity of fluorine atom, would reduce the electron donating property of $6 \mathrm{FdA}$ compared to that of DPM. The packing structure of $\mathrm{PI}(\mathrm{CBDA} / 6 \mathrm{FdA})$ is thought to be less ordered compared to $\mathrm{PI}(\mathrm{CBDA} / \mathrm{DPM})$ due to the steric constraint

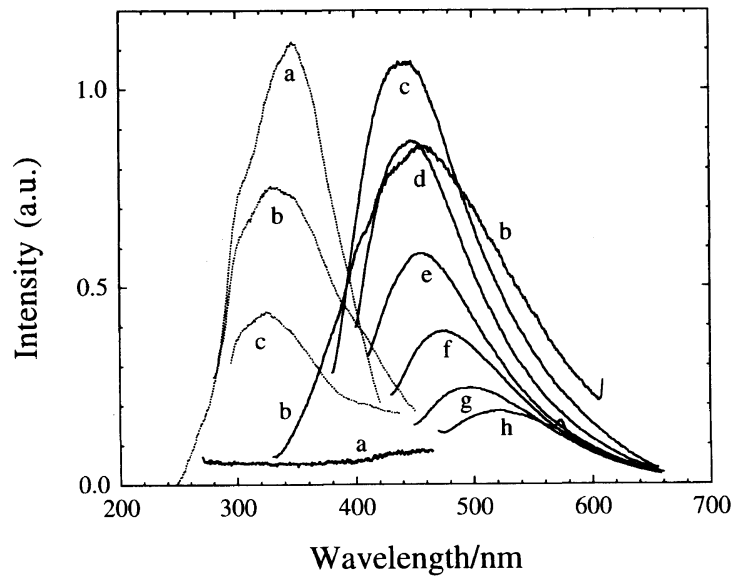

Figure 6. Fluorescence spectra of PI(CBDA/DPM) film $(50 \mu \mathrm{m}$ thick), - emission spectra excited at (a) $250 \mathrm{~nm}$, (b) $310 \mathrm{~nm}$, (c) $350 \mathrm{~nm}$, (d) $370 \mathrm{~nm}$, (e) $390 \mathrm{~nm}$, (f) $410 \mathrm{~nm}$, (g) $430 \mathrm{~nm}$, and (h) $450 \mathrm{~nm}$, respectively; -...-. excitation spectra monitored at (a) $449 \mathrm{~nm}$, (b) $500 \mathrm{~nm}$, and (c) $550 \mathrm{~nm}$, respectively.

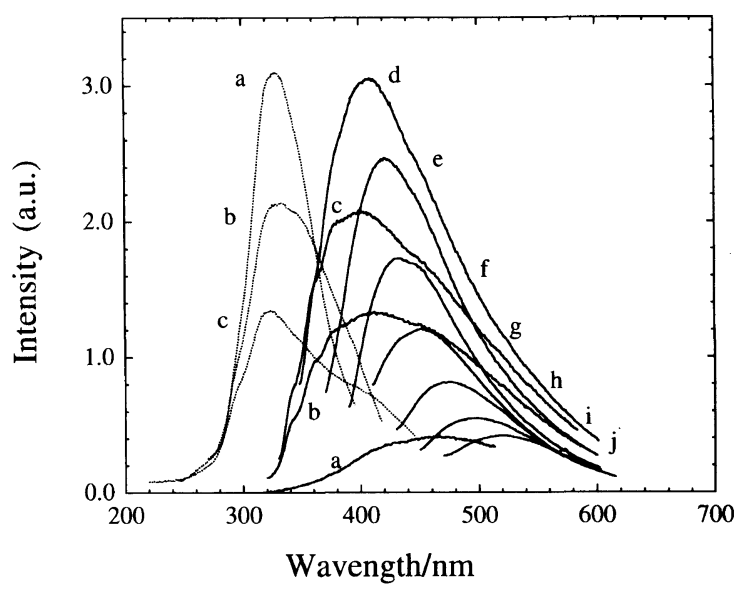

Figure 7. Fluorescence spectra of $\mathrm{PI}(\mathrm{CBDA} / 6 \mathrm{FdA})$ film $(50 \mu \mathrm{m}$ thick), - emission spectra excited at (a) $280 \mathrm{~nm}$, (b) $300 \mathrm{~nm}$, (c) $310 \mathrm{~nm}$, (d) $328 \mathrm{~nm}$, (e) $350 \mathrm{~nm}$, (f) $370 \mathrm{~nm}$, (g) $390 \mathrm{~nm}$, (h) $410 \mathrm{~nm}$, (i) $430 \mathrm{~nm}$, and (j) $450 \mathrm{~nm}$, respectively; -..-.-: excitation spectra monitored at (a) $405 \mathrm{~nm}$, (b) $450 \mathrm{~nm}$, and (c) $500 \mathrm{~nm}$, respectively.

resulting from the bulky $-\mathrm{C}\left(\mathrm{CF}_{3}\right)_{2}-$ group, and would be similar to that of PI(CBDA/DCHM). Both PI(CBDA/6FdA) and PI(CBDA/DPM) show one peak in their excitation spectra in Figures 6 and 7 , when they are monitored at different wavelengths. PI(CBDA/6FdA) and PI(CBDA/DPM) are supposed to form ground-state complexes with the head-to-tail stacking of imide rings in polymer backbones, where the contribution of charge transfer should also be considered because CBDA moiety acts as an electron acceptor, and 6FdA or DPM moiety acts as an electron donor.

\section{Thermal Properties of CBDA-Containing PI}

Figure 8 shows TG curves of PI(CBDA/DPM), PI(CBDA/6FdA), and PI(CBDA/DCHM) films. PI(CBDA/ DPM), PI(CBDA/6FdA), and PI(CBDA/DCHM) exhibited little weight loss from room temperature up to $440^{\circ} \mathrm{C}$. Above $440^{\circ} \mathrm{C}, \mathrm{PI}(\mathrm{CBDA} / \mathrm{DCHM})$ loses weight rapidly, and shows remaining weight of about $30 \%$ after heating to $500^{\circ} \mathrm{C}$, as a fully alicyclic polyimide. PI(CBDA/6FdA) shows decomposition at $441^{\circ} \mathrm{C}$, and 


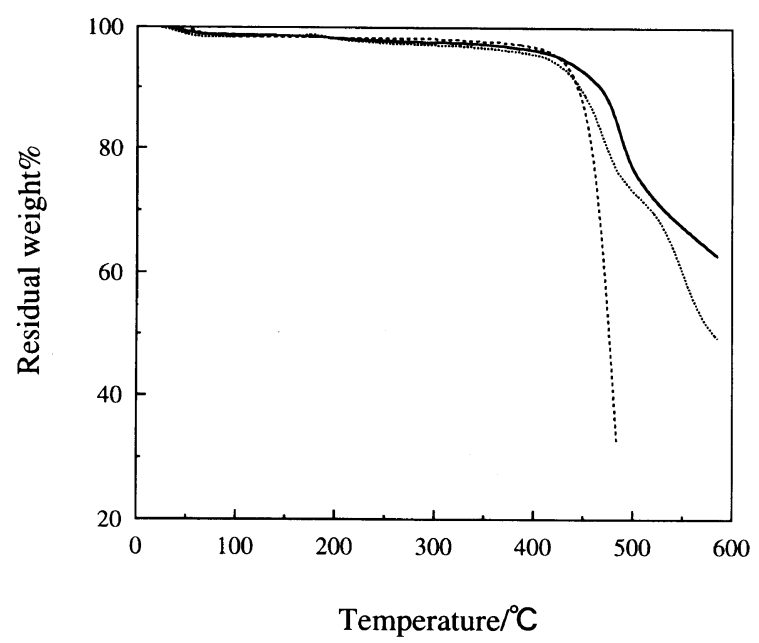

Figure 8. TG curves of $\mathrm{PI}(\mathrm{CBDA} / \mathrm{DPM})-\mathrm{PI}(\mathrm{CBDA} / 6 \mathrm{FdA})$ -----, and $\mathrm{PI}(\mathrm{CBDA} / \mathrm{DCHM})$--- in $\mathrm{N}_{2}$ with a heating rate of $10^{\circ} \mathrm{C}_{\mathrm{min}^{-1}}$.

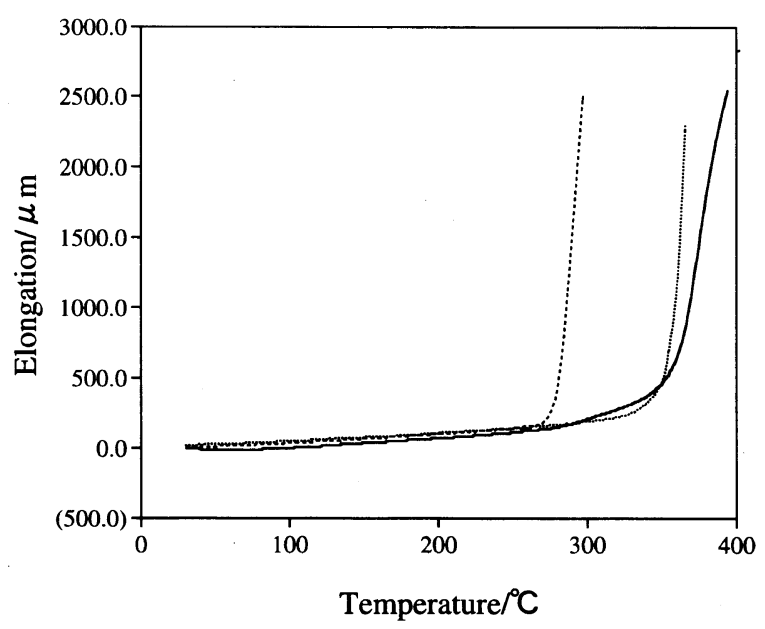

Figure 9. TMA curves of $\mathrm{PI}(\mathrm{CBDA} / \mathrm{DPM})-\mathrm{PI}(\mathrm{CBDA} / 6 \mathrm{FdA})$ -..--, and PI(CBDA/DCHM) --- in $\mathrm{N}_{2}$ with a heating rate of $10^{\circ} \mathrm{Cmin}^{-1}$, and under a fixed load $5 \mathrm{~g}$ for PI(CBDA/DCHM) and PI(CBDA/6FdA), $10 \mathrm{~g}$ for PI(CBDA/DPM).

then the slope becomes less steep at about $500^{\circ} \mathrm{C}$. The decomposition at $441^{\circ} \mathrm{C}$ is due to the decomposition of the moiety of CBDA, and the second change at $530^{\circ} \mathrm{C}$ would be due to the moiety of $6 \mathrm{FdA}$ which has a bulky group $-\mathrm{C}\left(\mathrm{CF}_{3}\right)_{2}-$. The remaining weight of PI(CBDA/ $6 \mathrm{FdA})$ is about $50 \%$ after heating to $600^{\circ} \mathrm{C}$. PI(CBDA/ DPM) loses weight quickly above $454^{\circ} \mathrm{C}$, and shows a remaining weight about $60 \%$ after heating to $600^{\circ} \mathrm{C}$. From the above data, we conclude that the decomposition is primarily due to decomposition of the alicyclic moiety.

The TMA curves of PI(CBDA/DPM), PI(CBDA/ 6FdA), and PI(CBDA/DCHM) films are shown in Figure 9. We obtained tough films of these polyimides by cooling under vacuum from the imidization temperature. In the case of PI(CBDA/6FdA), a tough film was obtained after imidization at $160^{\circ} \mathrm{C}, 200^{\circ} \mathrm{C}, 240^{\circ} \mathrm{C}$, and $300^{\circ} \mathrm{C}$ for $1 \mathrm{~h}$ each, which was used for TMA measurements. The films were elongated gradually with increasing temperature until their glass transition temperature, $T_{\mathrm{g}}$, is reached, where the films were elongated rapidly towards infinite. The glass transition temperature of PI(CBDA/DPM),
Table II. Summary of thermal properties of PI(CBDA/DPM), $\mathrm{PI}(\mathrm{CBDA} / 6 \mathrm{FdA})$, and PI(CBDA/DCHM)

\begin{tabular}{ccc} 
Sample & $\begin{array}{c}T_{\mathrm{d}} /{ }^{\circ} \mathrm{C} \\
\text { by TG }\end{array}$ & $\begin{array}{c}T_{\mathrm{g}} /{ }^{\circ} \mathrm{C} \\
\text { by TMA }\end{array}$ \\
\hline PI(CBDA/DPM) & 454 & 360 \\
PI(CBDA/6FdA) & 441 & 349 \\
PI(CBDA/DCHM) & 440 & 277 \\
\hline
\end{tabular}

$\mathrm{PI}(\mathrm{CBDA} / 6 \mathrm{FdA})$, and $\mathrm{PI}(\mathrm{CBDA} / \mathrm{DCHM})$ obtained from TMA curves are $360^{\circ} \mathrm{C}, 349^{\circ} \mathrm{C}$, and $277^{\circ} \mathrm{C}$, respectively. Compared to a conventional aromatic polyimide, e.g., PI(PMDA/DPM) with $T_{\mathrm{g}}=336^{\circ} \mathrm{C}$ by TMA, ${ }^{19}$ the introduction of alicyclic dianhydride CBDA into the polyimide main chains, did not change the $T_{\mathrm{g}}$ values so much. PI(CBDA/DPM) and PI(CBDA/6FdA) show essentially the same thermomechanical behavior under heating, whereas PI(CBDA/DCHM) shows $T_{\mathrm{g}}$ at a lower temperature, suggesting that the introduction of alicyclic DCHM, having trans-trans, trans-cis, and cis-cis isomers to the polyimide backbone affects the thermomechanical behavior of the polyimides owing to the existence of various non-coplanar packing structure.

The thermal properties of PI(CBDA/DPM), PI(CBDA/6FdA), and PI(CBDA/DCHM) measured with TG and TMA are summarized in Table II. These polyimides are thermally stable up to $440-450^{\circ} \mathrm{C}$ under the deaerated conditions and the stability is influenced by CBDA moiety. PI(CBDA/DPM) and PI(CBDA/6FdA) have very high $T_{\mathrm{g}}$ similar to conventional aromatic polyimides, while PI(CBDA/DCHM) shows its $T_{\mathrm{g}}$ at $277^{\circ} \mathrm{C}$.

DSC curves of these three polyimides films showed no substantial exotherms or endotherms in the temperature range of $50-350^{\circ} \mathrm{C}$.

\section{CONCLUSIONS}

Transparent polyimides derived from CBDA with DPM, 6FdA, or DCHM were successfully prepared. Their UV-Vis absorption and fluorescence spectra were investigated, compared with model compounds. All polyimides based on CBDA showed high transparency in visible region and no absorption was found above $375 \mathrm{~nm}$. Especially, PI(CBDA/DCHM) showed the highest transparency without almost any absorption above $310 \mathrm{~nm}$. The absorption at $235 \mathrm{~nm}$ of PI(CBDA/ DPM) and PI(CBDA/6FdA) was assigned to that of the phenylene group in diamine moieties. The fluorescence of all polyimides studied is attributed mainly to the excited ground-state complex. Excitation wavelength dependence of fluorescence peaks was observed, due to various conformation of packing structure. From the measurement of TMA and TG, PI prepared from CBDA show very high glass transition temperature, $T_{\mathrm{g}}$, in the region of $277-360^{\circ} \mathrm{C}$, and decomposition temperature around $450^{\circ} \mathrm{C}$. Thus, we conclude that introduction alicyclic dianhydride CBDA to the polyimides chains can prevent the formation of both inter- and intramolecular CT without reducing their thermal properties compared to corresponding aromatic polyimides.

Acknowledgment. We are indebted to Drs. H. Fukuro 
and M. Ishikawa of Nissan Chem. Co. for their kindly supplying the CBDA monomer.

\section{REFERENCES}

1. M. K. Ghosh and K. L. Mittal, Ed., "Polyimides: Fundamentals and Applications," Marcel Dekker, New York, N. Y., 1996.

2. Y. Tsuda, Y. Tanaka, K. Kamata, N. Hiroshi, S. Mataka, Y. Matsuki, M. Nishikawa, S. Kawamura, and N. Bessho, Polym. J., 29, 574 (1997).

3. T. Matsumoto and T. Kurosaki, Macromolecules, 28, 5684 (1995).

4. M. Kusama, T. Matsumoto, and T. Kurosaki, Macromolecules, 27, 1117 (1994)

5. K. Horie and T. Yamashita, Ed., "Photosensitivity Polyimides: Fundamentals and Applications," Technomic, Lascaster, PA, 1995.

6. H. S. Yu, T. Yamashita, and K. Horie, Macromolecules, 29, 1144 (1996)

7. J. A. Moore and A. N. Dasheff, Polym. Mater. Sci. Eng., 59, 999 (1988).

8. J. A. Moore and A. N. Dasheff, "Polyimides: Materials, Chemistry and Characterization," C. Feger, M. M. Khojasteh, and J. E. McGrath, Ed., Elsevier, Amsterdam, 1989, p 115.

9. J. A. Moore and A. N. Dasheff, Chem. Mater., 1, 163 (1989).

10. S. C. Freilich, Macromolecules, 20, 973 (1987).

11. S. A. Lee, T. Yamashita, K. Horie, and T. Kozawa, J. Phys. Chem. B, 101, 4520 (1997).

12. S. A. Lee, T. Yamashita, and K. Horie, Polym. J., 29, 752 (1997).

13. B. V. Kotov, T. A. Gordina, V. S. Voishchev, O. V. Kolninov, and A. N. Pravednikov, Vysokomol. Soyedin, A19, 614 (1977).

14. St. Clair and T. L. St. Clair, Polym. Mater. Sci. Eng., 51, 62 (1984).

15. St. Clair and W. S. Slemp, SAMPE J., 21, 28 (1985).

16. St. Clair and T. L. St. Clair, Polym. Mater. Sci. Eng., 55, 96 (1986).

17. St. Clair, T. L. St. Clair, and W. P. Winfree, Polym. Mater. Sci. Eng., 59, 28 (1988).

18. T. Matsuura, Y. Hasuda, S, Nishi, and N. Yamada, Macromolecules, 24, 5001(1991).

19. Q. Jin, T. Yamashita, K. Horie, R. Yokota, and I. Mita, J. Polym. Sci., Part A, Polym. Chem., 31, 2345 (1993).

20. Q. Jin, T. Yamashita, and K. Horie, J. Polym. Sci., Part A, Polym.
Chem., 32, 503 (1994).

21. T. Yamashita, Q. Jin, K. Horie, and R. Hayase, Rep. Progr. Polym. Phys. Jpn., 38, 375 (1995).

22. Q. Li, K. Horie, and R. Yokota, J. Photopolym. Sci. Techn., 10, 49 (1997).

23. F. Nakanishi, M. Hasegawa, and H. Takahashi, Polymer, 14 440, (1973).

24. H. Ohkita, A. Tsuchida, M. Yamamoto, J. A. Moore, and D. R. Gamble, Makromol. Chem. Phys., 197, 2493 (1996).

25. N. Koto, T. Abe, K. Otsuka, and H. Suzuki, Eur. Patent, 0130481A1 (1985).

26. K. W. Lee, S. H. Paek, A. Lien, C. Durning, and H. Fukuro, Macromolecules, 29, 8894 (1996)

27. C. E. Sroog, A. L. Endrey, S. V. Abramo, C. E. Berr, W. M Edward, and K. L. Olivier, J. Polym. Sci., Part A, Polym. Chem., 3, 1373 (1965).

28. M. Hasegawa, Y. Shindo, T. Sugimura, S. Ohshima, K. Horie, M. Kochi, R. Yokota, and I. Mita, J. Polym. Sci., Part B, Polym. Phys., 31, 1617 (1993).

29. D. F. Evans, J. Chem. Soc., 4229 (1957)

30. M. H. Kailani, C. S. P. Sung, and S. J. Huang, Macromolecules, 25, 3751 (1992)

31. Q. Li, T. Yamashita, K. Horie, H. Yoshimoto, T. Miwa, and Y. Maekawa, J. Polym. Sci., Part A, Polym. Chem., 36, 1329 (1998).

32. H. Itagaki, K. Horie, and I. Mita, Progr. Polym. Sci., 15, 361 (1990).

33. M. Hasegawa, M. Kochi, I. Mita, and R. Yokota, Eur. Polym. J., 25, 349 (1989); J. Polym. Sci., Part C, Polym. Lett., 27, 263 (1989).

34. H. W. Huang, K. Horie, T. Yamashita, S. Machida, M. Sone, M. Tokita, J. Watanabe, and Y. Maeda, Macromolecules, 29, 3485 (1996).

35. H. W. Huang and K. Horie, Trends Polym. Sci., 5, 407 (1997).

36. E. D. Wachsman and C. W. Frank, Polymer, 29, 1191 (1988).

37. P. S. Martin, E. D. Wachsman, and C. W. Frank, "Polyimides: Materials, Chemistry, and Characterization," C. Feger, M. M. Khojasteh, and J. E. McGrath, Ed., Elsevier, Amsterdam, 1989, p 371 .

38. J. M. Salley and C. W. Frank, "Polyimides: Fundamental and Applications, M. K. Ghosh, K. L. Mittal, Ed., Marcel Dekker, New York, N. Y., 1996, p 115 